\title{
THE IMPACT OF STATUS ANONYMITY ON TEAM DYNAMICS IN CO-CREATION WORKSHOPS
}

\author{
A. Lecuna Aguerrevere ${ }^{1,6, 凶}$, J. Alleblas ${ }^{2}$, R. M. Mueller ${ }^{3,4}$, M. Graves ${ }^{5}$ and \\ K. Thoring ${ }^{2,6}$ \\ ${ }^{1}$ Hochschule für Technik und Wirtschaft Berlin, Germany, ${ }^{2}$ Delft University of Technology, The Netherlands, \\ ${ }^{3}$ Berlin School of Economics and Law, Germany, ${ }^{4}$ University of Twente, The Netherlands, ${ }^{5}$ phi360, Germany, \\ ${ }^{6}$ Anhalt University of Applied Sciences, Germany \\ $\bigotimes$ alejandrolecuna@gmail.com
}

\begin{abstract}
This paper looks at the positive effects of partial status anonymity in face-to-face co-creation workshops. Results suggest that especially during the early phases of co-creation, i.e. idea generation, participants experience more freedom to express themselves without self-imposed barriers. We observed positive effects in terms of (1) lowering or even suspending the perceived status among team members, (2) increased motivation, (3) freedom to speak and positive disposition to listen, (4) willingness to consider perspectives from other team members.
\end{abstract}

Keywords: design thinking, collaborative design, design teams, innovation management, team dynamics

\section{Introduction}

One way of finding more resilient solutions to today's interrelated, complex, and networked challenges is by integrating more perspectives and opinions during the creative process. Research shows that heterogeneous teams produce more innovative and unique solutions to problems (BassettJones, 2005; Jackson, 1996). The co-creation approach proposes to bring the opinions and needs of all stakeholders into the creative process. Co-creation is perceived as both inclusive and dialectic, overcoming conflicts between stakeholders by aiming at solutions that synthesize divisive opinions, wants and needs (Sanders and Stappers, 2008). Recently, these approaches have crossed over from organisations and the workplace into the public sphere, as a way of deepening the dialogue between citizens and governments (Neulen, 2016). This ever-increasing variety of interests, and differences in stakeholder needs and socio-economic conditions, increases the complexity of co-creation activities, putting at risk the final outcomes.

Co-creation requires participants to closely work together and communicate based on durable relationships (Durugbo and Pawar, 2014). However, one common problem in co-creation activities, is the perceived difference of status, or expertise, held by each respective team member. These different degrees of status can cause the development of power structures and hierarchies within teams, which can lead to friction and obstructed team dynamics. These power structures, therefore, could be counterproductive, insofar as they affect the efficiency, creativity and overall team performance (Trischler et al., 2017; Mele, 2011). 
Studies show how these kinds of issues and struggles within product development teams can be addressed. De Dreu and Weingart (2003), for instance, suggest building higher levels of trust, openness, and psychological safety within the team through team building activities. These team building activities, however, are relatively time consuming and therefore more suited to long term projects. There is no prior research found on how to quickly ease or avoid the negative effects of status and power structures in teams during co-creation workshops.

One possible solution might be to introduce a design intervention whereby the participants' status are anonymised. Several studies have shown that anonymity in computer-mediated meetings can mitigate the negative effects of differences in status (e.g. Pissarra and Jesuino, 2005).

Our research addressed the need to find out:

$R Q:$ How status anonymity (our design intervention) affects team dynamics in faceto-face co-creation workshops.

Furthermore, we understand status to be a social consequence of identity formation in group processes. While individuals have a certain control over the communicated aspects of their identity, status is derived from assumptions concerning aspects of both this communicated or otherwise perceivable identity. Gender, age, dress, skin colour, and so forth, might all contribute to the perceived identity of an individual and might therefore affect their status. To fully anonymize participants, faceto-face communication would not have been possible. We therefore limited verbal communication of a person's professional identity, but the aforementioned elements of the participants' identities were not hidden. This means that assumptions about identity and therefore status might have been made during the co-creation process, but the participants were explicitly asked to refrain from verbally communicating their status amongst one-another.

This paper aims to add to the literature on co-creation and team dynamics by researching how social and intra-team hierarchical structures can be prevented through anonymising the status of team members. We worked from the hypothesis that people feel (more) free and creative when their social and professional status and identity have not been made public, and their function or role within a team has thus not been predetermined. We believe this should enable them to work more effectively in co-creation workshop teams.

\section{Theoretical foundations}

Relevant related work to our study is centred around four areas of interest: (1) co-creation and design thinking, (2) status and power in team dynamics, (3) constraints and creativity, and (4) anonymity in the creative process. For all four areas we present selected sources that form the theoretical foundations of our study. The insights from the related literature informed our own workshop challenge and design intervention.

\subsection{Co-creation and design thinking}

Co-creation practices, the democratisation of design processes, the introduction of the end-user into the early, conceptual phases of design, and the further engagement of all stakeholders, in order to create inclusive final products and services, have become popular since at least the 1990s (Sanders and Stappers, 2008). The design thinking methodology has been widely adopted as a means of conducting co-creative and user-centred projects. This methodology offers a structure, as well as simple rules and tools, which enable different stakeholders with different backgrounds to effectively interact and to cocreate with one another (Tschimmel, 2012).

\subsection{Status and power in team dynamics}

Status is a concept that is known from social psychology and describes "characteristics that lead groups to think about members in terms of their personal characteristics and contributions they can make to the task at hand" (Hollingshead, 1996). Status measures a social value (Sauder et al., 2012), that could be related to expertise, tenure, gender, or ethnicity (Hogg and Tindale, 2008, p. 565). Jackson, May and Whitney (1995) argue that group hierarchies are likely to create performance expectations, and which 
form the basis for hierarchies of power and prestige. These, in turn, may induce anxiety in team members with no relevant formal credentials. These types of feelings can have a negative impact on the overall creative process. According to Hogg and Tindale (2008, p. 565), group members with a lower status tend to seek acceptance by high-status members, therefore often seeking conformity with the latter's opinions. Moreover, low-status members may be reluctant to share relevant information, whereas high-status members may be less likely to take notice of information provided by low-status members. This situation can result in negative effects for the group's creative performance.

Several approaches have been developed to mitigate the negative effects of team hierarchy and power dynamics in idea generation and idea selection. Paulus (2000), for instance, argues that accountability and competition would reduce 'social loafing' and increase team productivity and creativity in work teams. Keum and See (2014) have proposed that team perceived hierarchical structure is detrimental in the idea generation phase, but beneficial for the selection of ideas. Earlier on, Smith (1998) identified four 'habit-breaking' idea generation strategies, such as the challenging of assumptions and changing of perspectives. Smith (1998) furthermore identified anonymity as a 'anti-inhibition enabler', to insure that 'ideas can't be traced back to their originators' (p.118). As a technique for this strategy, Smith (1998) mentions the collective notebook, referring to research done in 1962, before the widespread adoption of computers. Most research, however, focuses on computer-mediated interaction to ensure full anonymity.

\subsection{Constraints and creativity}

The co-creation design process can be seen as a series of activities with a set of constraints for positive impact. Sternberg and Kaufman (2010, p. 469), outlined constraints for the creation and development of ideas. They describe five major categories of constraints: the process, the person (or group of persons), the product, and time and contextual limitations. Having finished this categorisation, Sternberg and Kaufman (2010) argue that constraints often stimulate creativity rather than suppress it, arguing that more freedom is not necessarily better when it comes to creativity. Design thinking, for example, considers a series of stages which each have specific activities and objectives (Rowe, 1987). These specified stages could be considered positive constraints, as they structure and direct the creative process and keep the team focused. The brainstorming techniques to develop ideas, as outlined by Osborn (1953), act as a series of constraints for increasing the creative results of a group of people working together on a creative challenge. Caniéls and Rietzchel (2015) argue that constraints can make a problem or task more manageable, and possibly even more interesting. Moreover, constraints may entice employees to find a creative new way of circumventing obstacles and dealing with organisational barriers

\subsection{Anonymity in the creative process}

We introduce "status anonymity" as a potentially positive constraint in the creative process. Research on the positive effects of anonymity in electronic brainstorming sessions is extensive (Cooper et al., 1998; McLeod, 2011; Sosik et al., 1998). However, research that investigates the effect of anonymity in face-to-face activities, such as workshops or co-creation, is scarce. Evidently, in face-to-face meetings, some visible characteristics of a group member cannot be anonymised (such as age, gender, ethnicity). However, status-related aspects of expertise, tenure, and position can be withheld, and thus anonymised. This paper will investigate the effects of this partial form of "status anonymity".

\section{Methodology}

This research was addressed through action research using a qualitative and interpretative approach (Bradbury, 2015). We evaluated team dynamics inside a first co-creation workshop, and later introduced status anonymity in a second co-creation workshop and evaluated the changes in team dynamics. We conducted two co-creation workshops (A and B) in order to compare, evaluate, and test the effects of status anonymity on team dynamics. Both workshops were hosted by Innovation Forum Oxford at the University of Oxford Careers Service building. We developed one co-creation design challenge for each of the workshops. The participants came from the local community or nearby universities. They had different degrees of status, since they all brought with them varying degrees of 
expertise on the design challenge, through their professional background and position. There were directors, professors, $\mathrm{C}$-level managers, students, $\mathrm{PhD}$ candidates, bachelor students, junior managers. Both workshops followed the design thinking approach and took place with a one-month interval.

The purpose of the first workshop (A) was to observe and corroborate the common problematics reported by Mele (2011), that usually arise in teams while co-creating. Among the mentioned conflicts in group processes are task-related conflicts (different opinions regarding a task), process-related conflicts (controversies about how a task should be accomplished), role-related conflicts (different opinions about responsibilities and capabilities of group members), affective conflicts (emotional arguments based on interpersonal compatibility) and value-related conflicts (controversies caused by different values) (Mele, 2011). The purpose of the second workshop (B) was to test and observe the effects of status anonymity within diverse teams and to document the actual usefulness of this intervention. Both workshops and the respective observations are described in the following subsections. Table 1 outlines both workshop settings and participants.

Table 1. Overview of workshop settings

\begin{tabular}{|l|l|l|}
\hline & WORKSHOP A & WORKSHOP B \\
\hline Teams & 6 & 6 \\
\hline Coaches & 6 & 6 \\
\hline Participants & 30 & 32 \\
\hline Participants per team & 5 & $5 \times 4$ and 6 x 2 \\
\hline Location & $\begin{array}{l}\text { Oxford Careers Service building, } \\
\text { University of Oxford. }\end{array}$ & $\begin{array}{l}\text { Oxford Careers Service building, } \\
\text { University of Oxford. }\end{array}$ \\
\hline Duration & 1 Day (7 hours) & 1 Day (7 hours) \\
\hline Observations & Yes & Yes \\
\hline Interviews & No & Yes \\
\hline Co-creation Method & Design Thinking & Design Thinking \\
\hline Design Challenge & $\begin{array}{l}\text { Design the autonomous vehicle } \\
\text { experience for people living and } \\
\text { working in Oxford }\end{array}$ & $\begin{array}{l}\text { Design child health innovations } \\
\text { with special emphasis on medical } \\
\text { procedures and staff training in } \\
\text { the UK }\end{array}$ \\
\hline STATUS ANONYMITY & NO & YES \\
\hline
\end{tabular}

\subsection{Workshop A}

This workshop was conducted on-site at the University of Oxford's Careers Service building and hosted by Innovation Forum Oxford. Thirty participants attended the workshop. The total duration of the workshop was 7 hours. The participants had different professions and education backgrounds. Participants' professional background included academia, National Health System (NHS) staff, students, entrepreneurs, technology experts and NGO employees. Participants had little to no prior knowledge or experience in design thinking. The workshop started with a 20 -minute introduction, during which the participants learned about the design thinking methodology. The 5 steps model from Stanford University D.School model, (empathy, synthesis, ideate, prototype and test) was introduced, as well as the case study of the "embrace" infant warmer. The participants were also made familiar with the main characteristics of the design thinking method: problem re-framing, user centricity, comfort with ambiguity, collaboration, educated guessing, visualisation and creative problem solving. At the end of the introductory input the participants received the design challenge, which was to "design the autonomous vehicle experience for people living and working in Oxford". The design challenge was jointly created with local industry partners and local government representatives. There was a total of six teams, with five members each, and one design thinking coach per team. Before starting to work on the design assignment, the participants were given one minute each for introducing themselves, without limits on how much they could reveal. The workshop was conducted by two lead coaches and researchers and four coaches. During and immediately after the workshop, coaches 
observed and took written notes on team dynamics. The coaches paid specific attention to individual and team behaviour, performance during the challenge, whether the design thinking activities were being followed as explained, and the role that status played between the team members. These observations are described in the results section.

\subsection{Workshop B}

Workshop B took place on-site at the University of Oxford's Careers Service building, also hosted by Innovation Forum Oxford, with a total of thirty-two participants attending the workshop. The workshop lasted for 7 hours. The participants had different professional and educational backgrounds. These included technology experts and healthcare experts, medical doctors, NHS staff, as well as academics, students, design enthusiasts and professionals. Few of the participants had prior experience in design thinking. Six of the total thirty-two participants had attended the prior workshop (A). Each of those six participants were placed in teams where they did not know the other team members. As in workshop A, workshop B began with a 20 -minute introduction to the design thinking method following the Stanford University D.School model, followed by the "embrace" infant warmer case, then the characteristics of the design thinking methodology. Finally, they received their design challenge, which was to "design child health innovations, with a special emphasis on medical procedures and staff training in hospitals in the UK". The design challenge came from a childcare charity and a leading product design company. There was a total of four teams with five participants and two teams with six participants. Each team was accompanied by one design thinking coach.

In order to answer our research question, participants were anonymised in Workshop B. Upon arrival at the venue, participants were greeted and asked not to reveal information about their status, such as profession, expertise, job title, academic background or achievements, to one-another. During the introduction round, participants were only allowed to reveal their first names, which they wore as a name badge for the duration of the workshop, and briefly introduce their favourite hobbies. They were reminded to keep their identity and status secret until the end of the day, when they were finally allowed to reveal it to their fellow team members.

During and immediately after the workshop, coaches observed and took written notes on the perceived team dynamics. The coaches paid specific attention to individual and team behaviour, performance during the challenge, whether the design thinking activities were being followed as explained, and the role that status played between the team members. At the end of the workshop the coaches' notes were collected and semi-structured. On-site interviews were conducted with half of the participants. At least two members from each team were interviewed. The leading questions of the interviews were: in which parts of the creative process did it make sense being anonymous, and in which parts did it not make sense? The interviews were later transcribed, analysed by finding patterns and relationships, and compared with the written observations. Selected quotes and observations are summarised in the subsequent sections.

\section{Observations}

\subsection{Observations from workshop A}

\subsubsection{Expert knowledge sharing}

Participants who had prior knowledge about the challenge (autonomous driving) took time to share their knowledge with their respective teams. These conversations had to do with understanding the challenge from a theoretical perspective, as well as the many problems associated with it. This spontaneous knowledge sharing was valued by other participants, however it consumed valuable time.

\subsubsection{Hierarchies guiding decisions}

In three of the six teams, hierarchies played a significant role. Higher-status participants, like academics and experts, guided the team to what they considered to be the correct solution. These situations were perceived as patronising by other team members. The role of the hierarchies in teams overshadowed the contribution of some team members. These members became increasingly silent or 
did not participate in some of the activities. These different conflicts related to roles and values, correlating with the findings from Mele (2011). Coaches had to intervene in order to help the team overcome these internal power struggles and move forward. At the end of the workshop, one of the high-level participants expressed out loud his disappointment for not having had enough time to introduce himself in the morning. This feedback was positively received by part of the audience.

\subsubsection{Efficiency}

The same three teams that had issues with hierarchies also had difficulties performing and accomplishing activities within the designated timeframe and reaching the goals set for each phase. For example, two of the teams finished their prototypes fifteen minutes after the deadline and could not, therefore, get enough feedback from the testing sessions. The types of disagreements on how a task should be accomplished correlated with the findings from Mele (2011). However, all teams managed to receive feedback from users and present their final ideas to the audience. During the round of questions, answers came from those participants perceived as having a higher status in the team.

\subsection{Observations from workshop B}

\subsubsection{Following the rules in the morning and bending them in the afternoon}

During workshop B it was observed that team members followed the rule of not revealing their full identity during the morning hours unanimously. However, in the afternoon hours, the rules were bent by some team members. Medical doctors started to unveil crucial information in the second half of the day. "As the day went on, when people start thinking of solutions, I revealed more useful information. Then people started to realise that you knew more about it". However, experts still did not fully reveal their identity. Instead, they circumvented the rules. $\mathrm{A} \mathrm{PhD} \mathrm{candidate} \mathrm{and} \mathrm{medical} \mathrm{doctor} \mathrm{faced} \mathrm{the}$ issue of wanting to reveal crucial information without giving away his credentials, so he found a way: "I could not use my position as a training doctor, but ultimately, I managed to bring in my contribution. However, I could not precede it with any authority." He shared information instead by dodging full responsibility for and ownership of the information: "my understanding of the system in Australia is that this is how it happens". However, other team members bent the rules even more "I felt as a clinician there were times where I made really relevant points... I betrayed the anonymity rules later in the afternoon". We observed that other experts were sharing information in similar ways, either by asymmetric strategies or by simple verbal communication. Only one expert never fully revealed her professional identity and status to her team. Team members did not seem to be discouraged by this behaviour from the experts, but rather welcomed it.

\subsubsection{Efficiency}

The teams worked efficiently throughout the day. This was clear since they almost always completed tasks within the allocated timeframe. During team discussions and brainstorming, it was observed that team members were actively contributing, and no specific individual was dominating the group discussions. It was also observed that the teams managed to come up with more ideas than in workshop A. Participants worked more proactively: "...everybody took on things that you would not have asked them to do. We did not ask why we had to do this or that, people just did it." Teams were observed to be working louder, but always fostering a respectful spirit and fun atmosphere. Coaches noticed that no specific team members were drifting away from tasks; this had a positive impact on the efficiency and productivity of the teams. At the end of the day, all teams managed to accomplish the design challenge and to present their results.

\subsubsection{Hierarchies}

During the workshop, we observed that teams worked on an eye-to-eye level. Problems associated with hierarchies in teams were not observed or reported. Anonymising "was very good to even everyone out; everybody had an equal opportunity to speak out and say things." Participants were not interested in the statuses of their fellow team members. There were people with senior statuses in all 
teams, however, they did not dominate the co-creation process: "we did not feel obliged to listen because 'this guy is a consultant'; that did not happen." Coaches detected participants who were the driving force during specific moments in the process, but not all-round bosses. "In the UK, we are very hierarchical, especially when you look at a group of strangers creating, but if you do not know what they do professionally, you are more opinionated". For example, "...if I would have known that there were two paediatricians in the team, perhaps I would not have made that comment"; "if we had known this earlier on, we might have been quieter in voicing our opinions". It had an effect on the participants' moods "[...] not telling who we were definitely put us into the right [creative] mindset". "I like the idea of not being able to tell everyone about your background, because it breaks down the automatic questions we tend to ask each other, like 'what do you do?', 'where do you come from?', which aspects define your identity?". One participant told us, "This anonymous limitation made me think of other ways to qualify my statements, find different ways to back up what I was saying." The expert participants agreed that they did not withhold information, they just shared it in a different way.

\subsubsection{Playfulness}

We observed that most participants and especially those that were of high-level status enjoyed deceiving people: they perceived it as a game, rather than an annoying rule. "I think everyone took it as a little bit of a (positive) challenge. "I tried actively to find out undercover who was who, but I did not discover anyone's background... [laughs]". Although participants were trying throughout the day to find out who as in their team, this did not divert them from accomplishing the design challenge; instead, it kept them motivated. Interestingly, at the end of the day, when people were allowed to reveal their full identities, few had correctly guessed who was who. Some could approximately categorise fellow team members, but others did not guess at all.

\subsubsection{Freedom to speak and listen}

Participants felt liberated to speak out. Experts thought they could talk more openly and step out of the comfort zone of their own discipline: "As a doctor, you can only talk about your area of expertise. As a gastroenterologist, I would never talk about neurology, and so on, but here I felt more relaxed to talk about other areas." Experts welcomed not having to explain themselves, what their background is and what they were doing there, they felt this was "refreshing." On the other hand, non-experts felt free to speak and not immediately be judged: "I enjoyed that I could say whatever I want, and people would accept and take my opinion. That felt good...". A surprising result is that participants, regardless of their status, felt they listened more actively and considered the perspectives and ideas of others more carefully: "It made me think more broadly about the opinions of other people with different backgrounds. In the medical business, you get used to listening and evaluating opinions depending on where they are coming from; 'is this coming from a nurse or a doctor?'”. Not knowing each others' backgrounds forced participants to think twice about the perspectives, opinions and contributions of others: "Not being able to tell or ask those things, made me think about how I can add to the conversation, and how do I see other peoples' contributions.". Participants engaged in open, productive discussions and brainstorming sessions, during which everybody's perspective was brought in. During the solution testing rounds, status anonymity also played a liberating role. In the words of one medical doctor: "I thought it was interesting to go out [for a testing/feedback session with users], and not say who I was... if people knew who I was, they would have held back in their feedback." Expert participants also felt liberated while interviewing users: "If you have a problem that you are trying to present, and you are trying to explain it like a paediatrician, you might not get the user's real perspective." This freedom to listen enabled participants to step out of their own perspectives, and allowed users to give feedback without feeling intimidated by the status of the person presenting.

\subsubsection{Contradictions and negative feedback}

We observed and reported in the interviews that some of the participants would have liked to work without the anonymisation intervention. "Sometimes it made it hard to have a conversation with someone, if you don't know where someone is coming from, you don't know if their opinion and ideas are valid". However, on the other hand the same participant also told us that "it helps the team and 
people be more spontaneous, because you didn't know where people's opinions are coming from... this kept all very honest and neutral". However, "it would have been more comfortable if we would have known which kind of backgrounds we had because you can utilize each other's skill-set. If I knew that, it would have been a lot easier, but now I understand why we did it. [...] It was very good to even everyone out, everybody had an equal opportunity to speak out and to say things. But obviously, if we had known from the beginning who the experts were, we would have paid more attention to what they said." However, all in all, these kinds of contradictions did not seem to affect the way these participants worked or their engagement with the challenge.

\section{Discussion}

The present study contributes to the literature on team dynamics by investigating the impact of status anonymity in co-creation workshops. The observations indicate that status anonymity helped teams perform more efficiently, mainly in the idea generation phase. This was clear from the amount of ideas created, the increased will and freedom to share information, the openness to consider other participants' perspectives and the unexpected playfulness that participants displayed. Hence, we argue that status anonymity could have a positive impact on reducing the negative issues associated with hierarchies, status and power dynamics in teams, where it has been shown that hierarchies can negatively impact team performance (Jackson et al., 1995; Mele, 2011). However, further research is needed to validate this assumption.

Design practitioners and social scientists that need to bring different stakeholders' opinions and perspectives into the creative process, can use this intervention to enrich their workshops and ease the potential problems between team members with different backgrounds and statuses. For entrepreneurs, innovation-driven companies and start-ups who constantly develop user centric innovations, this intervention might enable them to work more efficiently with different stakeholders and focus groups, in order to get more sincere feedback. Educators who may want to involve business partners and project stakeholders in student projects can use this intervention to partially dissipate some of perceived differences between students and professionals, enabling them to work more efficiently and bring a touch of playfulness to their work. For politicians looking to involve citizens in co-creating urban projects or policy design, this intervention might help them receive more sincere opinions and reduce the polarization between groups with different political positions.

\section{Conclusions}

The results of the study yielded several insights on the impact of status anonymity on team dynamics. We observed positive effects in terms of (1) lowering or even suspending the perceived status among team members, (2) increased motivation, (3) freedom to speak and positive disposition to listen, (4) willingness to consider perspectives from other team members. However, also some negative effects could be identified: (1) status anonymity did not fully work when developing ideas in detail and (2) when expert knowledge was required. We suggest, therefore, using this intervention for the first, explorative phases of the design process in co-working workshops, when different perspectives are being considered and when ideas are being generated.

We were able to answer our research question: how does status anonymity (our design intervention) affect team dynamics in face-to-face co-creation workshops? However, we assume no direct, positive relation between team dynamics and team performance. Indeed, co-creation processes are complex and dynamic and status anonymity is not a cure all solution to perceived conflicts in groups. Furthermore, team performance in co-creation is a complex topic and the interaction between status anonymity and other drivers of team performance in co-creation has not been taken into account in this study.

There are some limitations to this study that need to be considered. The suggested status anonymity intervention was introduced and evaluated in only one workshop. The city of Oxford, where the workshop took place, can be described as a very traditional context, in which hierarchies and status rule the decision-making process. Another potential limitation of this study is that participants' different ages might influence how their status and level of expertise was perceived and positioned in relation to other team members. Both workshops also had different design challenges. The teams' 
compositions in terms of specific fields of expertise, personality types, background, and number of participants were not measured. These variables could have an impact on the effects of our intervention. We therefore consider this study a first step in the research on status anonymity in faceto-face co-creation workshops. Hence, we argue that we were able to cover the most important concepts of a corner case through this workshop, and that the results give an indication of the relation between anonymity and team dynamics. The research resulted in mostly positive feedback but at the same time, revealed insights on how to further improve this intervention.

Future research will focus on validating the transferability of this intervention to other contexts. Specifically, experts seemed to spontaneously bend their status anonymity in the afternoon, when expert information was needed. We will test a shorter version of our intervention, during which status anonymity is introduced in the morning session in a co-creation workshop, and suspended in the afternoon. By doing this, we will measure if we will enable expert knowledge to spread more efficiently and see if the team dynamics remain effective.

Furthermore, although all participants played along, some were asking for a rationale behind this intervention. Therefore, we will create a set of guidelines on why and how to be anonymous for a few hours. This guide could be given to participants upon arrival at the workshop or sent to them electronically before they arrive. Finally, surveys and in-depth follow-up interviews shall be conducted to further evaluate if status anonymity has a significant impact on overall team creativity in the idea generation phase.

\section{References}

Bassett-Jones, N. (2005), “The Paradox of Diversity Management, Creativity and Innovation”, Creativity and Innovation Management, Vol. 14 No. 2, pp. 169-175.

Bradbury, H. (2015), The SAGE Handbook of Action Research: Edited by Hilary Bradbury, Third edition, SAGE Publications, Los Angeles.

Caniëls, M.C.J. and Rietzschel, E.F. (2015), "Organizing Creativity: Creativity and Innovation under Constraints: Organizing Creativity”, Creativity and Innovation Management, Vol. 24 No. 2, pp. 184-196.

Cooper, W.H. et al. (1998), "Some liberating effects of anonymous electronic brainstorming", Small Group Research, Vol. 29 No. 2, pp. 147-178.

De Dreu, C.K.W. and Weingart, L.R. (2003), "Task versus relationship conflict, team performance, and team member satisfaction: A meta-analysis", Journal of Applied Psychology, Vol. 88 No. 4, pp. 741-749.

Durugbo, C. and Pawar, K. (2014), "A unified model of the co-creation process", Expert Systems with Applications, Vol. 41 No. 9, pp. 4373-4387.

Hogg, M.A. and Tindale, S. (2008), Blackwell Handbook of Social Psychology: Group Processes, John Wiley \& Sons.

Hollingshead, A.B. (1996), "Information Suppression and Status Persistence in Group Decision Making The Effects of Communication Media", Human Communication Research, Vol. 23 No. 2, pp. 193-219.

Jackson, S.E. (1996), “The consequences of diversity in multidisciplinary work teams”, In: West, M. A. (Ed.), Handbook of Work Group Psychology, pp. 53-75.

Jackson, S.E., May, K.E. and Whitney, K. (1995), "Understanding the dynamics of diversity in decision-making teams", Team Effectiveness and Decision Making in Organizations, Vol. 204, pp. 261.

Kaufman, J.C. and Sternberg, R.J. (2010), The Cambridge Handbook of Creativity, Cambridge University Press.

Keum, D.D. and See, K.E. (2014), "The Influence of Hierarchy on Innovation and Idea Selection: A Process View", Academy of Management Proceedings, Vol. 2014 No. 1, p. 10283.

McLeod, P.L. (2011), "Effects of Anonymity and Social Comparison of Rewards on Computer-Mediated Group Brainstorming", Small Group Research, Vol. 42 No. 4, pp. 475-503.

Mele, C. (2011), "Conflicts and value co-creation in project networks", Industrial Marketing Management, Vol. 40 No. 8, pp. 1377-1385.

Neulen, S. (2016), Co-Creation between Citizens and the Government: The Influence of Settings on the Intention to Join Co-Creation, Master's Thesis, University of Twente.

Osborn, A. (1953), Applied Imagination - Principles and Procedures of Creative Writing, Read Books Ltd.

Paulus, P. (2000), "Groups, Teams, and Creativity: The Creative Potential of Idea-generating Groups", Applied Psychology, Vol. 49 No. 2, pp. 237-262.

Pissarra, J. and Jesuino, J.C. (2005), "Idea generation through computer-mediated communication: The effects of anonymity”, edited by Gil, F. Journal of Managerial Psychology, Vol. 20 No. 3/4, pp. 275-291.

Rowe, P.G. (1987), Design Thinking, MIT Press. 
Sanders, E.B.-N. and Stappers, P.J. (2008), "Co-creation and the new landscapes of design”, CoDesign, Vol. 4 No. 1, pp. 5-18.

Sauder, M., Lynn, F. and Podolny, J.M. (2012), "Status: Insights from organizational sociology", Annual Review of Sociology, Vol. 38, pp. 267-283.

Smith, G.F. (1998), "Idea-Generation Techniques: A Formulary of Active Ingredients", The Journal of Creative Behavior, Vol. 32 No. 2, pp. 107-134.

Sosik, J.J., Avolio, B.J. and Kahai, S.S. (1998), "Inspiring group creativity: Comparing anonymous and identified electronic brainstorming", Small Group Research, Vol. 29 No. 1, pp. 3-31.

Trischler, J., Pervan, S.J. and Scott, D.R. (2017), "Exploring the 'black box' of customer co-creation processes", Journal of Services Marketing, Vol. 31 No. 3, pp. 265-280.

Tschimmel, K. (2012), "Design Thinking as an effective Toolkit for Innovation", ISPIM Conference Proceedings, The International Society for Professional Innovation Management (ISPIM), p. 1. 